\title{
Financial Classification of Listed Companies in China Based on BP Neural Network Method ${ }^{*}$
}

\author{
Shunquan Zhu \\ School of Finance, Guangdong University of Finance \& Economics, Guangzhou, China \\ Email: hdxgzsq@163.com
}

How to cite this paper: Zhu, S. Q. (2016). Financial Classification of Listed Companies in China Based on BP Neural Network Method. Journal of Financial Risk Management, 5, 171-177.

http://dx.doi.org/10.4236/jfrm.2016.53017

Received: June 12, 2016

Accepted: September 26, 2016

Published: September 29, 2016

Copyright (@) 2016 by author and Scientific Research Publishing Inc. This work is licensed under the Creative Commons Attribution International License (CC BY 4.0).

http://creativecommons.org/licenses/by/4.0/

\begin{abstract}
Based on analyzing and studying back propagation (BP) neural network method, the article takes 38 cross-section data as modeling sample, and uses 18 data at the same time as the examination sample to establish the financial distinction model. Passed through training and studies repeatedly to the sample, we obtained the more precise forecast result. The findings indicated: the BP neural network is one kind of nonlinear mapping model. In the situation that the degree of correlation among the indicators is high, or the data present nonlinearities change, or the data have omissions and so on, using BP neural network may obtain the quite satisfactory result, therefore it is a quite ideal forecast method, and has the widespread application scope and the high reference value.
\end{abstract}

\section{Keywords}

Financial Classification, BP Neural Network, Listed Companies in China

\section{Introduction}

The financial classification model refers to the mathematical model that can distinguish business financial condition and take suitable measure promptly through observing and analyzing some sensitive financial norms. For the investor and the Chief Financial Officer, they can make correct investment choice according to dynamic analysis of the financial classification index; but regarding to listed companies, they can reveal the question which exists in the financial management according to the above, and adjust the management strategy of company promptly, to avoid falling into ranks of ST, or PT.

*This paper is supported by Guangdong Provincial Scientific Plan Project (Soft Science, No.: 2015A070704058), Guangdong Provincial Universities' Social Science Foundation Project (No.: 2015WTSCX031), The Natural Science Foundation of Guangdong (No.: 2015A030313629), The Graduate Student Education Innovation Projects in Guangdong (No. 2-2015), and the National Natural Science Foundation of China. 
Beaver (1966) has conducted the preliminary research of the business bankruptcy question using the single variable analysis; Altman (1968) has conducted the research of US's business bankruptcy using the Fisher linear decision analysis for the first time, and has established the forecast model of business bankruptcy. Here we compute financial ratio using the financial targets in public financial report form, and then establish financial classification distinction model based on the method of neural network applying neural network method.

\section{Sample Selection}

Select sectional financial data of A-share listed companies in China in t-2 year. 38 pairs of samples are the modeling samples, 18 pair of samples are forecast sample.

1) The reason that the article did not consider using the data in financial report in $t-1$ year to forecast the condition of listed companies in $t$ year, is that the annual report disclosed system of listed companies in China has decided this kind of fact: Listed companies in $t$ year whether is ST or not is decided by their announcement of financial report in $\mathrm{t}-1$ year, therefore, the forecast model in $\mathrm{t}-1$ year, even if has enhanced the precision of forecast, also does not have too much value for application in actual forecast.

2) Considered the impact of profession factor, the article selects the manufacturing industry and the synthesis service listed companies as far as possible.

3) The material of China's A-share listed companies is complete. According to the stipulation, A-share listed companies carries out the domestic accounting standards and the accounting system, audited by the domestic accounting firm; B-share listed companies uses the international accounting standards, audited by the foreign capital Accounting firm. The achievement and other correlated data calculated by these two kind of accounting system and the auditing system have too much big deviation, thus has caused the financial material of the B-share corporate may not compared to A company's, and cannot build them simply in together as the object of empirical study. Data origin: CSMAR series research database.

\section{Selection for Financial Ratio}

\subsection{Quantitative Analysis of Financial Ratio}

Because of lacking the concrete instruction based on economic theory, it is difficult to carry on full description for financial difficult position using some simple financial ratio. Therefore we selects financial ratios as many as possible in the research process, these different ratios reflect different financial sides of the enterprise. We make the qualitative analysis separately to 14 financial ratios in 4 aspects as follows:

The targets that reflect the enterprise's financial capacity mainly include: The current ratio, the quick ratio, the working capital ratio that account for the total assets, but the targets that reflect the enterprise's long-term financial capacity include: Equity ratio, interest safeguard multiple and so on; The commonly used targets that reflect asset management capabilities include: The cycling rate of receivable account, the cycling 
rate of goods in stock, the cycling rate of total assets and so on; The targets that reflect enterprise's profit ability mainly include the net profit rate of the total assets, the main business income rate of increment, the net profit rate that account for shareholder rights and so on; The usually used major targets that reflect the cash flow include: The cash flow to debt ratio, the cash ratio accounted for main business income, the net profit rate of shareholder rights and so on.

At present, Some domestic scholars (for example, Zhao, Wang, \& Xiao, 2007; Zhang \& Cheng, 2005; Sun, 2013; Wu \& Lu, 2001; Zhu, 2004) think that the financial risks and the enterprise profit and loss have the inevitable relation, only uses related financial ratio in statement of profit and loss and the property debt table when model build, and little consider cash flow target that can immediately influence enterprise's turnover ability, but the practice proved that financial risks and profit and loss have not positive connection. Therefore, the reliability of model is very difficult to obtain guarantee, so it is suitable to use the targets that combine the tradition financial targets with the cash flows.

\subsection{Quantitative Analysis of Financial Ratio}

In order to analyze that the above financial ratio whether can effectively distinguish between ST Corporation and non-ST Corporation, we use statistical software SPSS to carry on the sample descriptive statistics, the variance Levene's test and the single variable T-test separately to each financial ratios of designated 54 pair of sample, through the experiment we discovered: In the selection 14 financial ratio, after carrying on screening using $\mathrm{T}$-test, the quick ratio, the cycling rate of goods in stock, the cycling rate of total assets, net profit rate of the total assets, the net profit rate that account for shareholder rights, the main business income rate of increment, the cash flow to the debt ratio, the cash ratio accounted for main business income and so on, the 8 financial norm's average value has the remarkable difference, and they may have the big function to explain the financial risks of listed companies in the future, therefore, we take these 8 financial ratios as the original variable of modeling based on neural network method.

\section{Neural Network Method and Step}

At present, the artificial neural networks have the most widespread application at aspects of pattern recognition, risk assessment, adaptive control. Hao (2001) pointed out that, as one kind of quite typical learning algorithm of the artificial neural networks, the BP method's primary structure is composed by an input level, one or many concealed levels, and an output level. Each level constituted by certain neurons (nodes), and the export value of each node decided by input value, action function and threshold value. Network's learning process includes forward-propagating for information and erroneous anti-propagation. In the forward-propagating process, the input information passes to the output level through the concealed level, after operation of action function it obtains comparison between the value of exports and the expected value, if it has the error, then the erroneous propagate reversely, returns along the original connecting path, 
and reduces the error through revising each neuron's weight in successive layers, and circulates like that until the output result meets the accuracy. Some neuron $(j)$ 's output $\left(O_{j}\right)$ on the BP neural network's concealed level and output level is determined by the equation below: $o_{j}=f_{j}\left(N e t_{j}\right)=f_{j}\left(\sum \omega_{j} x_{i}+\theta_{j}\right)$, in that, $f_{j}$ expressed that neuron $j$ corresponding excitation function, what at present uses to be most is the Sigmoid

function: $f(x)=\frac{1}{1+e^{-x}} ; \theta_{j}$ expresses the neuron $(j)$ 's threshold value; $x_{j}$ expresses input to each neuron $j ; w_{j}$ expresses the corresponding input and this neuron $(j)$ 's connection weight.

The BP network's storage information mainly manifests in two aspects: Firstly, network architecture, namely network input level, concealed level and the number of output level's node; Secondly, connecting weight value between neighboring level's node. The main parameter influencing network architecture is the number of concealed level's node, the studying rate $(\eta)$ and the system's error $(\varepsilon)$. The number of the input level and output level's node is decided by the system application, which is generally definite, but the number of concealed level's node is decided by the user's experience, if the number is too few, it will affect the network's validity, if the number are excessively many, it will increase the training time of the network by a large amount. The studying rate is usually between $0.01 \sim 0.9$, generally, the study rate is smaller, the training number of times are more, but if the studying rate is oversized, it will affect the stability of the network's architecture. Drafted error $(\varepsilon)$ usually needs to decide according to the output's request, and it is lower, the precision is higher. The summary of concrete step is as follows: 1) the BP network's initialization, determines the number of each level node, supposes the quite small random number for each weight value and the threshold value's initial value; 2 ) inputs the sample and the corresponding output, and carries on the study to each sample, namely carries on 3) to 5) process to each data in the sample; 3) figures out the actual output and neuron's output of the concealed level according to the inputting sample; 4) calculates differential value between the actual output and the expected output, obtains the error of the output level and the concealed level; 5) renews connecting weight value between the input level-concealed level's node, and between the concealed level-output level's node using the error which obtains according to the step $4 ; 6)$ obtains error function $\mathrm{E}$, judges $\mathrm{E}$ whether restrain to the given studying precision ( $\mathrm{E} \leq \mathrm{drafted}$ error), If satisfies, then the study finishes, otherwise, changes the step 2 to continue to carry on.

\section{Setting up Neural Network Model, Predicting and Testing Results}

\subsection{Scheme Stage}

BP neural network mode come true which mainly depends on the tool of Matlab language, and specific procedures at Appendix 3. For comparative studies, this article uses the six indicators which are the same original's financial indicators as a benchmark to confirm the input nodes of BP model, and output nodes for one. Output layer threshold 
is decided as $\mathrm{L}$ by network training. The selection of the hidden layer nodes is a complex problem, which is directly related with the number of input and output nodes. On the basis of reference experience formula: $2^{\mathrm{X}}>\mathrm{N}$ (X: hidden layer nodes, $\mathrm{N}$ : sample size), we can use "tentative test" method, first of all, fix a less hidden layer nodes and train, if a lot of training or the training at the number provided for no convergence, then stop training, and gradually increase hidden layer nodes, re-train and train the two cases a number of nodes 6 and 8 in hidden layer, and ultimately determine the number of hidden layer nodes is 8 . Therefore, the structure of BP network model is $8 \times 8 \times 1$.

\subsection{Training Stage}

Completion of the training and study sample in this stage, 112 Listed companies will be divided into training samples and test samples (38 pairs of samples as training, 18 pairs of samples as tested), then input system, based on BP method, the training $8 \times 8 \times 1$ network structure, select learning rate $\mathrm{G}=0.01$, system error $\mathcal{E}=10^{-4}$, the initial value of weights matrix are $8 \times 8$ bands and $8 \times 1$ random-order matrixes, where the random matrix's elements are randomly given by system. Through the Levenberg-Marquardt method, the article set up the model by the procedure of Matlab language. Procedures on the PC meet the requirements after 97 training cycles, the weight value matrix as $\mathrm{W}_{\mathrm{jh}}$ and $\mathrm{W}_{\mathrm{hi}}$, as well as the final threshold value as $\theta_{j}$ and $\theta_{i}$. Taking note of that different weight value's initial value can get different final numerical value through the training, but this does not affect the training results. One of input layers to hidden layer weight matrix is as follows:

$$
\begin{aligned}
& \text { [-3.8427 -1.3122 4.8056 5.034-1.2052-0.29493-6.5918 8.1441; } \\
& -6.37280 .600610 .466978 .1294-2.74631 .89698 .9805-1.6904 \text {; } \\
& -15.49858 .92139 .4728-5.7762-3.4767-2.4407-5.6261-6.6841 \text {; } \\
& 3.42012 .8741-3.6602-2.518-2.0942-4.5995-2.5758-1.0956 \text {; } \\
& 10.6784-1.0744-13.36035 .0875-0.038215-11.1925-7.9404-8.8715 \text {; } \\
& -7.10517 .48574 .13090 .69802-4.65242 .1134-11.54520 .37181 \text {; } \\
& -3.25954 .9273-7.49043 .7248-1.32934 .85174 .2182-13.244 \text {; } \\
& 11.489610 .43861 .17793 .29526 .6485-7.5523-4.924-16.8107] \text {. }
\end{aligned}
$$

Hidden layer to output layer weights matrix is as follows:

$$
\text { [20.2452 2.3206-40.715-5.4344-30.727 14.8085 27.9743 30.4184]. }
$$

Input layer to hidden layer threshold matrix is as follows:

$$
\text { [-2.6198; 16.5567; 5.5529;-11.5696; -7.3505; -7.5396;-2.0166;-0.11538]. }
$$

Hidden layer to output layer threshold matrix (threshold matrix is a real number):

[-5.2228].

The output results of the training are as follows:

$$
\begin{aligned}
& \text { [2.1917e-007 2.3241e-020 1.6579e-007 6.9618e-031 3.0972e-019 } \\
& 8.0496 \mathrm{e}-0113.1289 \mathrm{e}-0101.5326 \mathrm{e}-0073.3545 \mathrm{e}-0073.8288 \mathrm{e}-007
\end{aligned}
$$




$$
\begin{aligned}
& 8.6147 \mathrm{e}-0156.5765 \mathrm{e}-0076.0082 \mathrm{e}-0081.3499 \mathrm{e}-0115.8473 \mathrm{e}-013 \\
& 4.9569 \mathrm{e}-0071.1459 \mathrm{e}-0074.2467 \mathrm{e}-0071.6639 \mathrm{e}-0279.785 \mathrm{e}-008 \\
& 5.0444 \mathrm{e}-0074.3644 \mathrm{e}-0208.4875 \mathrm{e}-0071.3606 \mathrm{e}-0072.9396 \mathrm{e}-007 \\
& 4.753 \mathrm{e}-0077.7244 \mathrm{e}-0174.238 \mathrm{e}-0289.9938 \mathrm{e}-0082.6945 \mathrm{e}-007 \\
& 6.1013 \mathrm{e}-0096.126 \mathrm{e}-0079.1704 \mathrm{e}-0155.4379 \mathrm{e}-0075.5116 \mathrm{e}-020 \\
& 1.1682 \mathrm{e}-0085.0645 \mathrm{e}-0091.1607 \mathrm{e}-00611111111111111 \\
& 111111111111111111111111] .
\end{aligned}
$$

We can determine the output of $0<\mathrm{r}<0.5$ for the ST company and $0.5<\mathrm{r}=<1$ for the non-ST companies, which shows that the right rate of the two are $100 \%$.

\subsection{Prediction and Test Results}

In order to further test the application of accuracy of Model, we input testing sample data, and prediction results of the model are as follows:

$$
\begin{aligned}
& \text { [ } 1.3773 \mathrm{e}-0113.3873 \mathrm{e}-0060.000120614 .3471 \mathrm{e}-0057.4188 \mathrm{e}-023 \\
& 3.1345 \mathrm{e}-0306.002 \mathrm{e}-0051.8394 \mathrm{e}-0192.3365 \mathrm{e}-01114.0986 \mathrm{e}-007 \\
& 5.3364 \mathrm{e}-130.0001035312 .7226 \mathrm{e}-0163.5909 \mathrm{e}-0071.5338 \mathrm{e}-006 \\
& 1.2517 \mathrm{e}-022111112.7409 \mathrm{e}-010110.000193533 .3212 \mathrm{e}-017 \\
& \left.\begin{array}{llllllllllll}
1 & 1 & 1 & 0.8738 & 1 & 1 & 1
\end{array}\right] \text {. }
\end{aligned}
$$

Similarly, we can determine the output of $0<\mathrm{r}<0.5$ for ST company and $0.5<\mathrm{r}=$ $<1$ for the non-ST companies, the results of training and the prediction are shown in Table 1.

\section{Conclusion}

Among the selected 14 financial indicators, we use $\mathrm{T}$ test to filtrate and find that 8 financial indicators' averages are significant differences, such as: quick ratio, inventory turnover, total asset turnover ratio, net profit rate of total assets, rights and interests of net profit margin, growth rate of main business revenue, cash flow on the debt ratio, cash ratio of main business income, it's important to explain whether the listed company will have a greater financial risk in the future. So we put the 8 financial indicators as original variables of the modeling. Correct determinant rate of BP neural network

Table 1. The table of BP neural network model for prediction and testing to determine the results.

\begin{tabular}{ccccccc}
\hline & \multicolumn{3}{c}{ Training sample } & \multicolumn{3}{c}{ Prediction sample } \\
\cline { 2 - 6 } $\begin{array}{c}\text { Different } \\
\text { groups }\end{array}$ & $\begin{array}{c}\text { Actual } \\
\text { pair }\end{array}$ & $\begin{array}{c}\text { The number } \\
\text { of right } \\
\text { determinant }\end{array}$ & $\begin{array}{c}\text { Correct } \\
\text { rate }\end{array}$ & $\begin{array}{c}\text { Actual } \\
\text { pair }\end{array}$ & $\begin{array}{c}\text { The number } \\
\text { of right } \\
\text { determinant }\end{array}$ & $\begin{array}{c}\text { Correct } \\
\text { rate }\end{array}$ \\
ST & 38 & 38 & $100 \%$ & 18 & 16 & $88.9 \%$ \\
Non-ST & 38 & 38 & $100 \%$ & 18 & 15 & $83.3 \%$ \\
Correct & $100 \%$ & & & $86.1 \%$ & \\
determinant rate & & $100 \%$ &
\end{tabular}


model training samples is $100 \%$, which is a sign that BP neural network on the critical status of the company has strong ability to judge. In the circumstances that the indicators are a higher degree of inter-related, non-linear changes, BP neural network will still be able to fully study the information of the sample contained so that it can get a better result. So it has a wide application prospect and practical value to set up a financial risk analysis model fitting the condition in China by using neural networks intelligent method.

Using different neural network models and comparing their results are our further work.

\section{References}

Altman, E. (1968). Financial Ratios, Discriminant Analysis and Prediction of Corporate Bankruptcy. Journal of Finance, 23, 589-609. http://dx.doi.org/10.1111/j.1540-6261.1968.tb00843.x

Beaver, W. H. (1966). Financial Ratios as Predictors of Failure. Journal of Accounting Research, 4, 71-111. http://dx.doi.org/10.2307/2490171

Hao, L. P. (2001). Credit Analysis of Neural Network Modeling in Commercial Banking. System Engineering Theory and Practice, No. 5, 62-69.

Sun, Y. P. (2013). Financial Crisis Warning System Research of China's Water Treatment Listed Companies That Based on the Binary Logistic Regression Model. Economist, No. 2, 166-168.

Wu, S. M., \& Lu, X. Y. (2001). Prediction Model Research on China's Listed Company's Financial Distress. Journal of Finance and Economics, No. 6, 46-55.

Zhang, M., \& Cheng, T. (2005). The Empirical Study on Predicting Financial Distress from Dynamic Perspective. Journal of Finance and Economics, No. 1, 63-72.

Zhao, X., Wang, L. J., \& Xiao, Z. 2007). Financial Early Warning Empirical Study of Real Estate Public Companies. Journal of Southwest Jiaotong University: JCR Social Science Edition, No. 2, 102-106.

Zhu, S. Q. (2004). Evaluation Research on Listed Companies' Financial Status Based on the Method of Factor Analysis. Statistics \& Information Forum, 4, 44-48.

Submit or recommend next manuscript to SCIRP and we will provide best service for you:

Accepting pre-submission inquiries through Email, Facebook, LinkedIn, Twitter, etc.

A wide selection of journals (inclusive of 9 subjects, more than 200 journals)

Providing 24-hour high-quality service

User-friendly online submission system

Fair and swift peer-review system

Efficient typesetting and proofreading procedure

Display of the result of downloads and visits, as well as the number of cited articles

Maximum dissemination of your research work

Submit your manuscript at: http://papersubmission.scirp.org/

Or contact jfrm@scirp.org 